\section{Is peer review unbiased?}

Sir — The thrust of your leading article "Conflict of interest revisited" (Nature 355, 751; 1992) is based on the false premise that academic researchers not associated with the business world are unbiased expert participants in peer review panels of national agencies. Bias is a matter of degree, and whether conscious or unconscious it depends heavily on the goals, rewards and penalties that shape the framework of the expert's views. The academic researcher seeks the accolades of his professional colleagues, and depends on such recognition for promotion, tenure, professional awards and grants from government agencies and foundations. The politics of science reveals the extent of the manipulations by individual scientists to achieve these rewards. For most academics, these are more persuasive inducements than the money flow from business affiliations. The recent flurry of investigations into the ethics of scientists discloses the great value placed on these non-monetary goals.

Expertise in scientific specialties resides in those who work in depth in their fields, whether in academic institutions or industry. Such work almost always requires substantial financial support, either from government agencies and foundations or from industrial organizations. All these funding groups have goals that they assume will be furthered by the scientists they support, even though all avow that they seek only the truth. It is generally recognized in academic circles that government agencies are not likely to support those whose opinions might weaken the agencies' budget submissions to their government. Similarly, industry is very uncomfortable with research findings that question its public positions.

Does this pose a serious problem for advisory boards and peer review panels, as your leading article stated? Not if the myth of unbiased academic opinion is recognised. These boards and panels need the very best of expert knowledge, wherever it resides. The individual views and opinions that arise from each scientist's working relations are best disclosed and balanced by assuring a mix of experts. It must be recognized that every scientist, whether in an academic institution or industry, places maximum value on professional credibility. For this reason, in a mixed expert group a consens is on fact finding is usually arrived at without stress. Bias based differences usually occur in the area of policy implications, and it is here that the virtues of a mix of backgrounds becomes evident in disclosing the range of views of the various stakeholders. That is what decision-makers need to know to balance national interests. So the problem your leading article poses would not exist if the self-serving image of academic objectivity was not so deeply embedded in academia and national institutes.

\section{Chauncey Starr}

Electric Power Research Institute,

Palo Alto, California 94303, USA

\section{SLAC defended}

SIR - I write in response to the two articles "Z-not" and "Zero-sum game" (Nature 356, 99 \& 97; 1992). The Stanford Linear Collider (SLC) had two major goals - to develop a new technology for electron-positron colliding beams that would allow the eventual contruction of much higher energy machines at much lower costs than the old storage-ring technology, and to do some physics with this machine. The SLC has achieved its first goal, proving the feasibility of the technique to the point where large groups in Europe, Japan and Russia are now working with us to develop the technology for future linear colliders. Further experiments scheduled on the SLC are crucial to this international programme.

With regard to $\mathrm{Z}$ production, no one at SL.AC to my knowledge has ever thought that the SLC could beat LEP in the raw number of $\mathrm{Zs}$ produced. Our niche was always going to be polarized beams. Although we have been late in reaching this goal, we agreed to a new set of milestones with the Department of Energy (DOE) in May 1991, and have so far exceeded all of them. We may fail, but haven't yet.

The other article in the same issue refers to a proposal that we have made to the DOE to build a B-Factory which the US high-energy physics community has said is extremely important to science. "Understanding the origin of CP violation is one of the central goals of particle physics," wrote the High Energy Physics Advisory Panel last year, one that "can be addressed in much more depth by the $\mathrm{e}^{+} \mathrm{e}^{-}$machines than by hadron colliders". There is also great interest elsewhere in such a facility, as evidenced by major groups in Europe and Canada that have expressed an interest in collaboration on experiments at the B-Factory. Unfortunately, there can be no funds available for such a project from the National Science Foundation until 1997 at the earliest, and no new $\mathrm{DOE}$ money for the foreseeable future.

In such circumstances, SLAC and its user community arrived at the proposal to do the B-Factory out of the current budget by considering how to do the best possible physics for the funds available. SLAC is on target to meet its new goals, and we expect to be producing some unique physics next year.

\section{Burton Richter}

(Director)

Stanford Linear Accelerator Center, PO Box 4349

Stanford, California 94309, USA

\section{Brownian motion}

SIR - Cadée ${ }^{1}$ disagreed with my argument that Robert Brown did not observe brownian motion ${ }^{2}$, noting “. . . that his [Brown's] particles were too large (for example pollen grains). ..". The phrase in parentheses is Cadée's, which he then used to negate my contention ${ }^{2}$. Brown reported vigorous motion with both $1 /$ $4,000-1 / 5,000$-inch $(6-5 \mu \mathrm{m})$ and $1 /$ 30,000 -inch $(1 \mu \mathrm{m})$ particles and with bismuth, manganese and even lead particles - clearly he did not observe proper brownian motion. Cadee's authority, Ford $^{3}$, reported only a few qualitative experiments, compared to Jean Perrin's well-known, comprehensive, quantitative work ${ }^{4}$.

Cadée suggested that repetition of Brown's methodology with one of Brown's original microscopes, as Ford did, proves that Brown observed brownian motion. I doubt the interpretation, not the observation. Particle motion in Brown's methodology is too vigorous by orders of magnitude to be proper brownian motion. Following Ford, this simple demonstration illuminates the problem: a small drop of 10:1 diluted India ink is examined, uncovered, with a modern compound microscope, with cross-hairs in the eyepiece, at $100 \times$. Vigorous motion of the particles will be seen. But if another drop is covered with a cover glass supported by two cover glasses, to form a cell $0.1 \mathrm{~mm}$ deep, virtually no motion will be observed. Pseudobrownian motion might describe the particle motion reported by Brown and Ford, whereas brownian motion is retained for the particle motion recorded by Perrin.

My serendipitous discovery regarding Brown's work arose from my 15-year examination of some of the foundations of physics. I am preparing a lengthy historical paper on Brown's work and brownian motion.

Daniel H. Deutsch

141 Kenworthy Drive,

Pasadena, California 91105, USA

1. Cadée, G. C. Nature 354, 180 (1991)

2. Deutsch, D. H. Bull. Am. Phys. Soc. Abstr. 36, 1374 (1991).

3. Ford, B. J. Single Lens 149-150 (Harper \& Row, New York, 1985).

4. Perrin, J. Brownian Movement and Molecular Reality 1-93 (Taylor \& Francis, London, 1910). 